\title{
The Views of Family Members about Nursing Care of Psychiatric Patients Admitted at a Mental Hospital in Malawi
}

\author{
Genesis Chorwe-Sungani1 ${ }^{*}$, Mbumba Namelo², Vincent Chiona², Ditress Nyirongo² \\ ${ }^{1}$ Community and Mental Health Nursing Department, University of Malawi, Blantyre, Malawi \\ ${ }^{2}$ Zomba Mental Hospital, Zomba, Malawi \\ Email: " genesischorwe@kcn.unima.mw
}

Received 23 February 2015; accepted 10 March 2015; published 13 March 2015

Copyright (C) 2015 by authors and Scientific Research Publishing Inc.

This work is licensed under the Creative Commons Attribution International License (CC BY).

http://creativecommons.org/licenses/by/4.0/

(c) () Open Access

\begin{abstract}
Family members of a mentally ill person play a crucial role in the recovery of their sick relative. They care for their sick relatives at home and in hospital. Some views of family members indicate that they get satisfaction from participating in nursing care of their sick relative. The aim of this study was to describe the views of family members about nursing care of psychiatric patients admitted at a mental hospital in Malawi. A qualitative study design was used and data were collected from ten participants through in-depth interviews. Ethical approval was granted by relevant authorities. Data were analysed using Colaizzi method. The findings fell into the following four themes that emerged: family participation in nursing care; nurses' skills and experience in caring; respect for psychiatric patients and interactions and information sharing. This study offers valuable information about the views of families regarding nursing care of psychiatric patients. They are involved in the care of their sick relatives although there is lack of effective cooperation between them and nurses. The lack of collaboration made families receive inadequate information about their sick relative. Therefore, it is imperative that nurses are competent in implementing family involvement in nursing care.
\end{abstract}

\section{Keywords}

Family Involvement, Views, Nursing Care, Psychiatric Patient

\section{Introduction}

Malawi is located in southern part of Africa and her population is approximately 16 million people. It is appar*Corresponding author. 
ent that $28.8 \%$ of people who seek medical help from primary care settings in Malawi have some form of a mental health problem [1]. Mental health problems contribute about $4.3 \%$ of the global disease burden in the country [2]. However, there are no adequate mental health professionals in the country and mental health services are scanty in many rural areas. The country has 0.01 Psychiatrist per 100000 and 0.22 Nurses per 100000 working in mental health sector [2]. There are very few community mental health activities which take place in the communities and hence many patients end up being admitted at mental hospitals which are far away [3]. The country has one government mental hospital, one government psychiatric unit, one missionary mental hospital [4]. In addition, mental health services are integrated in general health care delivery system so that people with mental health problems can access treatment in general settings [5]. Family members play a part in the care of psychiatric patients who access treatment in the aforementioned health care settings.

Family members of a mentally ill person play a crucial role in the recovery of their sick relative [6]. Some views of family members found in literature indicate that they get satisfaction from caring for their sick relatives and feel more close to them as they participate in nursing care [7]. On the other hand, it is documented that families experience problems in relating to health professionals and they feel ignored and excluded from the care [8]. This is supported by Blomqvist \& Ziegert who postulated that families view that they do not get cooperation from nurses and feel alienated from the nursing care being provided [9].

Family is an entity in which people start their developmental process [10] and it is also unit of care [11]. In Africa, severely ill people rely on and live with their extended family [12]. This is usually the case in Malawi where family members care for their sick at home and in hospital. The family members who participate in the care of the mentally ill patients are parents, uncles, aunts, siblings, children, friends and significant others. These family members help nurses to understand the illness of their relative and identify effective interventions that facilitate recovery [8]. However, it is evident that families are not viewed as priority for nurses when caring for psychiatric patients [9]. Nurses often do not work together with family members of a psychiatric patient when providing nursing care [13] [14]. Conversely, recent literature suggests that nurses must include families in the nursing care because both a sick individual and his family are patients [15].

Family members suffer when living with a relative who has mental health problems and their psychological wellbeing worsen alongside that of their sick family member [16]. Mental illness of a family member can negatively influence the emotions of the whole family and other family members may develop their own health problems such as distress, sense of burden [9] sadness and guilt [6]. This is corroborated by Rose and colleagues who asserted that families experience considerable amount of stress and burden that negatively affect health of entire family [17]. One can argue that family members of a person who is mentally ill should be viewed as having their own needs which require the attention of nurses. They carry a huge burden and sometimes feel that they are blamed for illness of their relative [6] [8]. It is evident that family members sometimes fail to deal with their own individual or family needs because they focus on their sick relative [7]. As such, nurses must provide support to the family when it is faced with these difficult circumstances [10]. This may cause family members to feel better and satisfied with the nursing care the family is receiving.

It is evident that family members who are satisfied with nursing care have less difficulty in coping with the illness of their relative [18]. Family members experience increased levels of burden when they do not have sufficient coping resources [19]. They can acquire effective coping skills when they are involved in the nursing care of their relative. The involvement of the patient, family and community helps in facilitating the provision of safe and effective mental health care [12] that deals with their needs. Nursing care that does not address needs and likings of patients and their relatives may be deemed as burdensome by family members. These family members experience greater burden if they do not get adequate support and help from their immediate environment [18]. For instance, some families of psychiatric patients do not seek mental health care early due to fear of being stereotyped and ostracized [20]. Nurses can effectively deal with these fears by pyschoeducating family members and community on mental health issues [12]. Psychoeducation can change people's behaviours or perceptions through teaching, communication and problem solving [8]. This may help psychiatric patients and their families to view that they are receiving holistic nursing care.

The studies from elsewhere have given us an insight on family involvement and views of family members regarding the nursing care of psychiatric patients. But there is scanty information on the same from a Malawian perspective. Therefore a study was conducted to uncover the views of family members about nursing care of psychiatric patients who are admitted at a mental hospital in Malawi. 


\section{Methodology}

\subsection{Design}

This study utilized a qualitative study design to uncover the views of family members about nursing care of psychiatric patients who are admitted at a mental hospital in Malawi.

\subsection{Study Setting}

The setting for this study was a mental hospital in Malawi. This setting was appropriate because family members are allowed to come and visit their sick relatives and this made it easier for the researchers to recruit the study participants who came to see their sick family member.

\subsection{Participant Recruitment}

Recruitment of participants in this study was purposive to select participants who had experienced the phenomenon understudy. Thus family members for psychiatric patients who had come to visit their sick relative at the mental hospital were recruited if they were $=>18$ years old and they had made $=>2$ visits to the mental hospital. Five men and five women were included in the study to create relatively homogenous sample that was representative of both genders. The researchers approached the family members to explain the study to them and answer their questions about the study. Those who accepted to participate in the study were asked to sign a written consent.

\subsection{Ethical Considerations}

The study proposal was submitted to College of Medicine Research and Ethics Committee for ethical approval and institutional clearance was sought from the Director of a mental hospital where this study was conducted. The researchers explained the nature and benefits of the study to family members of psychiatric patients and recruited only those who volunteered to participate in the study. They assured participants of confidentiality by not collecting participants' identification particulars as part of data. A written informed consent was obtained from family members who accepted to participate in this study. They were informed that they were free to withdraw if there would be anything that would make them feel uncomfortable during the course of the study. Their privacy was respected by interviewing them in a private room within the hospital.

\subsection{Data Collection Procedure}

The study collected data through in-depth interviews using interview guide which was designed by researchers and experts from the Faculty of Nursing at Kamuzu College of Nursing. The questions on the interview guide focused on the views of family members about nursing care of psychiatric patients. Family members of psychiatric patients were personally invited to participate in the study. The study was explained to them; they were allowed to ask questions and the researchers answered those questions. Those who accepted to participate in the study signed a written consent and were allowed to see their relatives before being interviewed. The interviews were conducted in a quiet and secluded room within the hospital. These in-depth interviews lasted for 30 to 60 minutes and were audio recorded. The interviewers asked the participants particulars first and they were not audio recorded. Then, the interviewers audio recorded the participant's responses regarding their views about nursing care of psychiatric patients. The interviews were conducted in Chichewa because it is spoken and understood by many Malawians.

\subsection{Data Analysis}

Data were analysed using Colaizzi’s method which has the following six stages [21].

\subsubsection{Stage 1: Acquiring a Sense of Each Transcript}

In this stage, the researchers closely read and re-read all the participants' oral descriptions with the overall aim of immersing themselves in the data and developing a preliminary understanding of the meaning of the data. This begun the process of prolonged engagement with the data which continued until the point at which the 
study report was complete. The researchers listened to each interview six times and read and re-read the transcripts on eight different occasions in order to gain a sense of each participant's views about nursing care of psychiatric patients. They also wrote notes of their impressions, thoughts and responses in the margins of each transcript on each occasion of reading and re-reading. These notes were discussed amongst themselves and formed the basis for the next step of extracting significant statements.

\subsubsection{Stage 2: Extracting Significant Statements}

The researchers engaged themselves with reading and re-reading each transcript to identify statements and phrases which were expressing the participants' views about nursing care of psychiatric patients. These statements were highlighted on each page of the transcript and later copied and pasted on a separate page with the page and line numbers attached. The copying and pasting of statements enabled the researchers to re-read the pasted statements and thus they focused on identifying emerging themes. Significant statements and phrases from the transcripts of the participants' views about nursing care of psychiatric patients were identified, highlighted and extracted. Thereafter, similar statements were combined; repetitions were eliminated and a list of non-overlapping non-repetitive statements was developed. The researchers manually extracted the significant statements in order to facilitate their on-going emersion in the data [22].

\subsubsection{Stage 3: Formulating Meanings}

In this stage, significant statements were grouped into the following four larger units of meaning or themes that emerged: family participation in nursing care; nurses' skills and experience in caring; respect for psychiatric patients and interactions and information sharing. A table with the formulated meanings and their associated significant statements was developed to facilitate this stage of the analysis.

\subsubsection{Stage 4: Organising Formulated Meanings into Cluster of Themes}

Formulated meanings (themes) were organised into clusters of themes. The principles of texture and structure in phenomenological analysis were used as an aid to clustering the meanings [21]. The texture cluster were broken down further into different aspects of the "what" of the experience including the feelings and thoughts that formed part of the texture of family members views about nursing care of psychiatric patients.

\subsubsection{Stage 5; Exhaustively Describing the Investigated Phenomenon}

The final stage of the data analysis involved the development of an exhaustive description of the phenomena; integrating the textural and structural descriptions into a coherent and holistic picture of family members views about nursing care of psychiatric patients.

\subsubsection{Stage 6: Returning to the Participants}

This step is one of the strategies that were used to validate the exhaustive descriptions with the participants. The exhaustive descriptions were compared to the participants' audio taped interviews. Both the exhaustive descriptions and the audio taped interviews were compatible and represented the views of family members about nursing care of psychiatric patients. Furthermore, the researchers were expected to return to the participants to converse on their exhaustive descriptions. However, they were not able to achieve this because some participants were from another district and others could not be traced.

\section{Findings}

\subsection{Demographic Characteristics}

Participants in this study comprised of 10 family members of psychiatric patients who came to see their relative at a mental hospital of which 5 were male and 5 were female (Table 1 ). They were all married and their ages ranged from 39 to 58 years.

\subsection{Main Findings}

The findings of this study fell into the four themes that emerged form data. These were: family participation in nursing care; nurses' skills and experience in caring; respect for psychiatric patients; and interactions and information sharing. 
Table 1. Demographic characteristics of participants.

\begin{tabular}{cl}
\hline Demographic characteristic & $\mathrm{n}$ \\
\hline Highest level of education & 3 \\
Primary education & 6 \\
Secondary education & 1 \\
Tertiary education & \\
Home district & 8 \\
Zomba & 1 \\
Blantyre & 1 \\
Lilongwe & \\
Occupation & 3 \\
Peasant farmer & 1 \\
Soldier & 4 \\
Business persons & 1 \\
Sales representative & 1 \\
House wife & \\
Tribe & 3 \\
Yao & 2 \\
Chewa & 2 \\
Ngoni & 3 \\
Nyanja & 1 \\
Religions & 3 \\
Roman Catholic & \\
Islam & 3 \\
Seventh day Adventist & \\
Showers of Blessings & \\
\hline & \\
Church Central Africa Presbyterian & \\
\hline
\end{tabular}

\subsubsection{Theme 1: Family Participation in Nursing Care}

Family members reported that they participate in nursing care of psychiatric patients admitted at the mental hospital. One family member said: "Yes we are taking part in the care, to comfort him so that maybe he should feel that we are together, that we are not discriminating against him and inside my heart I feel good because I know I am helping my own grandfather". Even though family members are involved in the care of psychiatric patients, it was clear that their participation was limited to bringing food, assisting with bathing and encouraging patient to receive medications. The following comment summarises the views of many participants: "On taking part in the care, we come here three times a day. We come in the morning with breakfast, we bath her and change clothes if necessary, at midday give her lunch, we bring the patient what she wants. If it ever happens that he is refusing medication, we encourage him to take treatment".

\subsubsection{Theme 2: Skills and Experience in Caring}

Family members felt that nurses are caring and know their job. A family member said: "I was amazed that nurses could move around with another person and find the patient who did not come to collect the medicines. I saw that they are not annoyed with patients". Similar views were expressed by another family member who said: "This kind heart of nurses makes us happy as we know patients are in good hands". Family members viewed nurses as being skillful in their job. One family member reported that: "They first see, examine the patient and give him the right medicine according to the disease, you find a nurse chatting with a patient, not that he is giving medical treatment but through that chat he can find some problems that the patient has". However, some family members were not happy with nurses who do not show interest in the condition of their patients. A family member felt that "some nurses are not concerned with the care of patients; I say there is no attention towards the patients. She cannot take a bath on her own and instead of forcing her to take a bath, they just leave her". They were also concerned with the ill treatment that some patients receive: For instance, family member com- 
plained that: "patients are not handled well when they are causing trouble, I think the treatment they are given is not good."

\subsubsection{Theme 3: Respect for Patients}

Family members said that they were not happy with lack of respect for psychiatric patients. A family member reported that: "sometimes nurses say unkind words to patients and some patients isolate themselves to a certain place and start crying when they hear such words". They proposed that nurses ought to show love, respect and sense of humor to patients. One family member said this about nurses: "They have to change, start showing love to patients. It is good to respect patients because if you don't respect them they can be sad every day. But when they are respected like when calling them by name, it is something good because when they hear that; they feel that they are humans".

\subsubsection{Theme 4: Interactions and Information Sharing}

Relationships: The family members had varied views regarding their encounters with nurses. Some felt that they interacted well with nurses although some were of the contrary view. A family member reported that: "our relationship with the nurses is good and there is no problem". However, some contrasting views were expressed by a family member reported that: "these people do not interact with family members, yet we want to hear updates on the progress of the patient when we come here". In addition another family member lamented that "sometimes we meet other nurses who are rude towards us when we come here".

Information: It was clear from the findings that some family members felt that they got information from nurses. A family member said that "nurses share with us what we are supposed to do; I can say that nurses helped us a lot as far as advice is concerned. I feel good in my heart because the advice we are given is very important and appropriate". On the other hand family members also reported that they were unsatisfied with information they get from nurses about their sick relative. A family member said: "We don't know anything, like is there any improvement in the patient? This hurts. It could be better if we are told about the condition of our child when we come to visit". Family members indicated that it is not easy to get information from nurses. These views were expressed by a family member who said that "it is hard to ask for information because nurses are not easily accessible. But often times we meet these trainees. If we hear any information, it is from the men wearing safari suits (Hospital Attendants)". It was clear from the findings of this study that family members do not receive adequate information about their sick relative in the course of nursing care. One family member said: "We will get the advice about our sick relative on the discharge day".

\section{Discussion}

Family members participate in the nursing care of their relatives who are admitted at a mental hospital. They feel more comfortable, needed and wanted when helping their sick relative [18] [23]. This is encouraging because family members have an essential responsibility of providing care and support to their mentally ill relatives [17]. In this way, they facilitate recuperation of their sick relative. Nurses view family members as a support in psychiatric care and a helper who makes their caring easier by providing information about the patient [9]. It is evident that involving family members in nursing care of their mentally ill relative may help in reducing morbidity and mortality [14]. As such, families should take responsibility in the nursing care being provided to their sick relative [10].

For this to happen, there must be mutual dependence and relationships among all people that are involved in the care [6]. Nevertheless, some family members in this study felt that their involvement in nursing care is limited. Families feel marginalised, and isolated from the nursing care when they are not involved in the planning process [13]. This may be true for some family members in this study who felt that there is little or no engagement with the nurses when caring for psychiatric patients. Nurses may not collaborate with families when they have inadequate knowledge about family involvement in psychiatric nursing [24]. As such, family members and the nurse may not effectively contribute towards the patients' recovery if they do not collaborate when planning nursing care. This is contrary to Blomqvist and Ziergert who asserted that families and nurses should work together when planning nursing care [9]. This is made possible when nurses are knowledgeable and skilled in caring for patients and their families.

In this study, family members felt that nurses had the necessary skills for providing care to patients. The 
nurses were viewed as having good interpersonal skills and being able to assess and treat patients. They also reported that nurses are kind although some do not show interest towards their patients and do not collaborate with families. It is apparent that some mental health workers such as nurses lack experience and knowledge in working with family members of their mentally ill patients [14]. This may be the case at a mental hospital in Malawi where family involvement is rarely implemented. Eassom and colleagues claimed that lack of skills and confidence by nurses is a barrier to family involvement [13]. There is a need to train these nurses in family nursing so that they can be competent and confident in working with families so that patients can receive quality nursing care [24] and feel respected.

In this study family members felt that nurses are kind although sometimes they meet nurses who are rude. They demanded that nurses must show respect to patients by providing humane treatment. Nurses need to respect family members [8] and their sick relative. Family members said that nurses can show respect by calling patients by their names. They further said that lack of respect hurts patients' feelings. Respect for families and patients may help in the creation of partnerships with the nurses which among other things promote information sharing. It is clear from the findings of this study that family members wanted to receive information about their sick relative from nurses. Some family members felt satisfied with the information given to them by nurses because it helped them to care for their mentally ill relative. Contributors to nursing literature suggest that encounters between family members and nurses should include sharing of information that helps families to effectively care for patient [9]. However, family members in this study felt that it is not easy to get information from nurses because they do not avail themselves.

Families experience problems in getting information from nurses and feel excluded from the care [14]. Sometimes nurses do not interact with families because they are viewed as a burden to them [6] and it takes a concerted effort of families to interact with them [17]. This hinders communication of pertinent information between family members and nurses. Family members need adequate information about mental illness, treatment, discharge and symptoms of relapse and being given hope about patient recovery [9] so that they can fully participate in the care. They feel dissatisfied with nursing care of their mentally ill relative when they perceive that there is lack of information and support from nurses [14]. It can be logical to say that nurses must continuously provide relevant information about patient condition to the families which can help them to cope with the burden of their relatives' condition. Families need supportive interactions with nurses to manage their care giving burden and care for their sick relative [17].

\section{Conclusion}

This study provides valuable information about the views of families regarding nursing care of psychiatric patients. They indicate that they are involved in the care of their sick relatives although there is lack of effective cooperation between them and nurses. The lack of collaboration with nurses has made families receive inadequate information about the condition of their mentally ill relative. Therefore, it is imperative that nurses are equipped with necessary knowledge and skills for implementing effective family involvement in nursing care that deals with individual patient needs and those of the family.

\section{Acknowledgements}

We thank all family members who participated in this study.

\section{References}

[1] Kauye, F. (2008) Management of Mental Health Services in Malawi. International Psychiatry, 5, 29-30.

[2] Kauye, F., Chiwandira, C., Wright, J., Common, S., Phiri, M., Mafuta, C., Maliwichi-Senganimalunje, L. and Udedi, M. (2011) Increasing the Capacity of Health Surveillance Assistants in Community Mental Health Care in a Developing Country, Malawi. Malawi Medical Journal, 23, 85-88

[3] WHO (2011) Mental Health Atlas 2011. http://www.who.int/mental_health/evidence/atlas/profiles/mwi_mh_profile.pdf?ua=1

[4] Chorwe-Sungani, G. (2013) Nurses’ Knowledge and Skills in Providing Mental Health Care to People Living with HIV/ AIDS in Malawi. Journal of Psychiatric Mental Health Nursing, 20, 650-654. http://dx.doi.org/10.1111/jpm.12062 
[5] Chorwe-Sungani, G., Shangase, N. and Chilinda, I. (2014) Care of Patients in Malawi Who Have HIV/AIDS and Mental Health Problems. Mental Health Practice, 17, 35-39. http://dx.doi.org/10.7748/mhp2014.04.17.7.35.e849

[6] Sjoblom, L., Pejlert, A. and Asplund, K. (2005) Nurses’ View of Family in Psychiatric Care. Issues in Clinical Nursing, 14, 562-569. http://dx.doi.org/10.1111/j.1365-2702.2004.01087.x

[7] Brady, N. and McCain, G.C. (2004) Living with Schizophrenia: A Family Perspective. Online Journal of Issues in Nursing, 10. http://dx.doi.org/10.3912/OJIN.Vol10No01HirshPsy01

[8] Bland, R. and Foster, M. (2012) Families and Mental Illness: Contested Perspectives and Implications for Practice and Policy. Australian Social Work, 65,517-534. http://dx.doi.org/10.1080/0312407X.2011.646281

[9] Blomqvist, M. and Ziergert, K. (2011) Family in the Waiting Room: A Swedish Study of Nurses Conceptions of Family Participation in Acute Psychiatric Inpatient Settings. International Journal of Mental Health Nursing, 20, 185-194.

[10] da Silva, K.V.L.G. and Monteiro, A.R.U. (2011) The Family in Mental Health: Support for Clinical Nursing Care. Revista da Escola de Enfermagem da USP, 45. http://dx.doi.org/10.1590/S0080-62342011000500029

[11] Leahey, M. and Harper-Jaques, S. (2010) Integrating Family Nursing into a Mental Health Urgent Care Practice Framework: Ladders for Learning. Journal of Family Nursing, 16, 196-212. http://dx.doi.org/10.1177/1074840710365500

[12] Alem, A., Jacobsson, L. and Hanlon, C. (2008) Community-Based Mental Health Care in Africa: Mental Health Workers' Views. World Psychiatry, 7, 54-57.

[13] Eassom, E., Giacco, D., Dirik, A. and Priebe, S. (2014) Implementing Family Involvement in the Treatment of Patients with Psychosis: A Systematic Review of Facilitating and Hindering Factors. BMJ Open, 4, Article ID: e006108.

[14] Kaas, M.J., Lee, S. and Peitzman, C. (2003) Barriers to Collaboration between Mental Health Professionals and Families in the Care of Persons with Serious Mental Illness. Issues in Mental Health Nursing, 24, 741-756. http://dx.doi.org/10.1080/mhn.24.8.741.756

[15] Bell, J.M. (2009) Family Systems Nursing: Re-Examined. Journal of Family Nursing, 15, 123-129. http://dx.doi.org/10.1177/1074840709335533

[16] Robinson, W.D., Springer, P.R., Bischoff, R., Geske, J., Backer, E., Olson, M., et al. (2012) Rural Experiences with Mental Illness: Through the Eyes of Patients and Their Families. Families, Systems, \& Health, 30, 308-321. http://dx.doi.org/10.1037/a0030171

[17] Rose, L.E., Mallinson, R.K. and Walton-Moss, B. (2004) Barriers to Family Care in Psychiatric Settings. Journal of Nursing Scholarship, 36, 39-47. http://dx.doi.org/10.1111/j.1547-5069.2004.04009.x

[18] Kuuppelomaki, M., Sasaki, A., Yamada, K., Asakawa, N. and Shimanouchi, S. (2004) Family Carers for Older Relatives: Sources of Satisfaction and Related Factors in Finland. International Journal of Nursing Studies, 41, 497-505. http://dx.doi.org/10.1016/j.ijnurstu.2003.11.004

[19] Chadda, R.K., Singh, T.B. and Ganguly, K.K. (2007) Caregiver Burden and Coping: A Prospective Study of Relationship between Burden and Coping in Caregivers of Patients with Schizophrenia and Bipolar Affective Disorder. Social Psychiatry and Psychiatric Epidemiology, 42, 923-930. http://dx.doi.org/10.1007/s00127-007-0242-8

[20] Seloilwe, E.S. and Thupayagale-Tshweneagae, G. (2007) Community Mental Health Care in Botswana: Approaches and Opportunities. International Nursing Review, 54, 173-178. http://dx.doi.org/10.1111/j.1466-7657.2007.00525.x

[21] Creswell, J.W. (2007) Qualitative Inquiry and Research Design, Choosing among Five Approaches. 2nd Edition, Sage Publications Inc., Thousand Oaks.

[22] Terr Blanche, M., Durrheim, K. and Painter, D. (2006) Research in Practice: Applied Methods for Social Sciences. 2nd Edition, UCT Press, Cape Town.

[23] Andren, S. and Elmstahl, S. (2005) Family Caregivers' Subjective Experiences of Satisfaction in Dementia Care: Aspects of Burden, Subjective Health and Sense of Coherence. Scandinavian Journal of Caring Sciences, 19, 157-168. http://dx.doi.org/10.1111/j.1471-6712.2005.00328.x

[24] Sveinbjarnardottir, E.K., Svavarsdottir, E.K. and Savaman, B.I. (2011) Nurses Attitudes towards the Importance of Families in Psychiatric Care Following an Educational and Training Intervention Program. Journal of Psychiatric and Mental Health Nursing, 18, 895-903. http://dx.doi.org/10.1111/j.1365-2850.2011.01744.x 